Revista de Derecho

\title{
La naturaleza como sujeto de derechos y su interpretación constitucional: interculturalidad y cosmovisión de los pueblos originarios
}

Nature as a subject of rights and its constitutional interpretation: Interculturality and worldview of original peoples

\author{
Alexander Barahona Néjer \\ Docente Universidad Católica de Cuenca, Ecuador \\ alexbarh_22@hotmail.com \\ ORCID: 0000-0002-8913-5467
}

Alan Añazco Aguilar

Docente e investigador de la Facultad de Ciencias Sociales y Jurídicas

Universidad Internacional SEK (UISEK), Ecuador

alan_oaa@hotmail.com

ORCID: 0000-0002-6222-8831

DOI: https://doi.org/10.32719/26312484.2020.34.3

Fecha de recepción: 6 de noviembre de 2019

Fecha de aceptación: 7 de enero de 2020

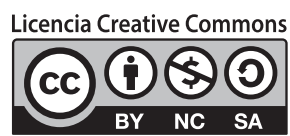




\section{RESUMEN}

El presente artículo contribuye a la construcción de un método constitucional que considere al principio del sumak kawsay y sus elementos en la interpretación de la naturaleza como sujeto de derechos, tanto en la jurisprudencia como en la deóntica jurídica. De esta forma, se plantea a la interculturalidad como fundamento de una epistemología que amalgame las diversas cosmovisiones que conjuga la Constitución. Por lo tanto, en un primer momento, se abordará la relación sumak kawsay-naturaleza, exponiendo las nociones que, desde la cosmovisión indígena, fundamentan su reconocimiento como sujeto de derechos. Posteriormente, se analizará la especial relación que los pueblos libres o en aislamiento voluntario tienen con la naturaleza, aproximándonos a su cosmovisión a fin de incorporar su enfoque en la hermenéutica constitucional. Finalmente, como corolario, se enfatiza en la dimensión pragmática de la interpretación intercultural y su relevancia en el paradigma constitucional ecuatoriano.

PALABRAS CLAVE: naturaleza, pueblos libres, sumak kawsay, interpretación, hermenéutica, epistemología.

\section{ABSTRACT}

This article contributes to the construction of a constitutional method that I considers about sumak kawsay rule and its elements in the interpretation of nature as a subject of rights, both in jurisprudence and legal ethics. In this way, interculturality is considered as the foundation of an epistemology that amalgamates the various worldviews that conjugates the Constitution. Therefore, at first, will be approached the sumak kawsay-nature relationship, exposing the notions that, from the indigenous worldview, base its recognition as a rights subject. Subsequently, will be analyzed the special relationship that free people or voluntary isolation peoples have with nature, approaching their worldview in order to incorporate their focus on constitutional hermeneutics. Finally, as a corollary, the pragmatic dimension of intercultural interpretation and its relevance in the Ecuadorian constitutional paradigm is emphasized.

KEYWORDS: nature, uncontacted tribes, sumak kawsay, interpretation, hermeneutic, epistemology. 


\section{INTRODUCCIÓN}

【 a Constitución de la República en los artículos 10, 71 y 72 reconoce a la naturaleza como sujeto de derechos. Este reconocimiento, en términos formales, constituyó para la época de expedición de la Constitución un avance dentro del constitucionalismo. Decimos para la época en la medida que, en la actualidad -si bien no como texto constitucional-, se han expedido actos normativos y decisiones judiciales, en Nueva Zelanda ${ }^{1}$ y Colombia, ${ }^{2}$ por ejemplo, en las que se han reconocido derechos a ríos y a un páramo. De ahí que los avances constitucionales van dando cuenta de la necesidad de dotar a la naturaleza de atributos fundamentales, propios de su esencia, preservación y desarrollo, a fin de garantizar formal y materialmente su protección en las particulares dimensiones que sus derechos se manifiestan.

La naturaleza como sujeto de derechos implica (desde una visión occidental de los derechos) la obligación de respeto, garantía y protección. Estos objetivos se proponen como retos en la formulación de política pública, expedición de normativa y en la tutela judicial. En estas tres dimensiones, la medida en la que se materializarán los derechos de la naturaleza depende del enfoque epistémico con el que se las estructure. Así, un enfoque antropocéntrico nos acerca a la naturaleza como fuente de consumo a la cual debemos reintegrar -en la mejor medida posible- sus recursos para la subsistencia de la sociedad (fundamento del desarrollo sustentable); por tanto, resulta excluyente, utilitarista y no concibe a la naturaleza como sujeto sino como objeto de protección (indeterminada), siendo el ser humano el eje central de los derechos y cuya satisfacción se ha mercantilizado en detrimento de lo natural (la paradoja de la protección de lo que se debe destruir).

Al contrario, un enfoque intercultural tiene como objeto el conjugar la visión de consumo, expuesta en el párrafo precedente, con la de convivencia complementaria. Este enfoque parte de un diálogo de conocimientos y saberes -resaltando la necesaria protección de la naturaleza para una subsistencia humana, como la importancia

1. BBC Mundo, "Whanganui, el río en Nueva Zelanda que tiene los mismos derechos que una persona", accedido 30 de octubre de 2019, https://www.bbc.com/mundo/noticias-39291759.

2. El Tribunal Administrativo de Boyacá reconoció que el Páramo de Pisba es sujeto de derechos.

*Colombia Tribunal Administrativo de Boyacá, "Sentencia”, en Juicio de tutela n. 1523833330022018 0001601,9 de agosto de 2018.

De igual forma, la Corte Constitucional de Colombia en sentencia T-622/16 reconoció al río Atrato, su cuenca y afluentes como una entidad sujeta de derechos.

*Colombia Corte Constitucional, "Sentencia T-622/16", en Expediente n. ${ }^{\circ}$ T-5.016.242, 10 de noviembre de 2016. 
intrínseca de este ente- encontrando compatibilidades, a manera de alternativas, que permitan acercarnos a la naturaleza como sujeto y parte de una vida biodiversa.

Este ejercicio de construcción epistémica implica una complejidad fundamental, el de arribar a puntos de encuentro entre dos visiones en principio opuestas. Para contextualizar, una hermenéutica ha de incorporarse formal y materialmente; formalmente en el diseño legal, por lo que, el parlamento juega un papel dirimente en la construcción de un enfoque intercultural en la lógica deóntica del ordenamiento jurídico. Asimismo, el intérprete de la Constitución, al ser el órgano que dota de contenido los derechos con carácter autoritativo, constituye un actor -aunque precario- que ha de esgrimir los mínimos fundamentos de esta interpretación, a la que la Constitución se refiere como integral.

Entonces, la jurisprudencia constitucional, a falta de acuerdo parlamentario, constituye la única herramienta que delimita los contornos del contenido interpretativo de la naturaleza como sujeto de derechos, sin embargo, hasta la fecha, la corporación constitucional se ha referido únicamente respecto a la legalidad de explotación de recursos no renovables (sentencia . $^{\circ}$ 218-15-SEP-CC), sin analizar en mayor medida el contenido y alcance del derecho.

Así, sin normativa parlamentaria respecto al derecho a la naturaleza ni desarrollo jurisprudencial que delimite su contenido, el presente trabajo procura contribuir a un método que ayude a entender las diversas implicaciones del reconocimiento de la naturaleza como sujeto de derechos y así contribuir a un adecuado tratamiento de la naturaleza bien por el legislador como por el máximo órgano de administración de justicia constitucional.

\section{LA NATURALEZA COMO SUJETO DE DERECHOS. UNA INTERPRETACIÓN DESDE EL SUMAK KAWSAY}

El artículo 427 de la Constitución determina "Las normas constitucionales se interpretarán por el tenor literal que más se ajuste a la Constitución en su integralidad" al condicionar la interpretación a la integralidad del texto, los derechos de la naturaleza han de ser leídos desde una perspectiva que incorpore al sumak kawsay, siendo, quizá, este principio el que nos permita desentrañar el sentido y alcance del precepto (en principio indeterminado) dado que las cosmovisiones indígenas abonaron en mayor medida a este reconocimiento constitucional.

Es oportuno precisar que el debate respecto a la construcción del sumak kawsay, resulta todavía un debate complejo e inacabado, pues, pese a los múltiples intentos -desde varias visiones o matrices epistemológicas- de definirlo y limitarlo, todavía no es posible arribar a posiciones concluyentes -comúnmente aceptadas-o, al 
menos, a denominadores comunes que coadyuven a un consenso. Por el contrario, sigue siendo un concepto complejo e indeterminado y cuyo uso o significación, a veces contradictorio, resulta moldeable o acomodaticio, en la medida que está atado a las posiciones ideológicas o a las corrientes de pensamiento a las que uno se adscriba y las finalidades, a partir de las cuales se lo aborde.

En este ejercicio deliberativo se planeta que existen tres corrientes respecto al sumak kawsay, a saber:

1. Socialista-estatista, se centra en la gestión política del Estado y en la equidad social como objetivo, dejando de lado cuestiones culturales o ambientales. Dentro de esta corriente el sumak kawsay deja de ser solo un planteamiento surgido de las nacionalidades indígenas y necesariamente requiere ser complementado por otras matrices epistemológicas como el socialismo del siglo XXI, por ejemplo.

2. Ecologista, se caracteriza por la relevancia que se presta a la preservación de la naturaleza y a la necesaria participación de los distintos sectores de la sociedad en la construcción y definición del sumak kawsay.

3. Indigenista, se caracteriza por la relevancia que se da a la autodeterminación de los pueblos indígenas en la construcción del sumak kawsay y a los elementos espirituales de la cosmovisión andina. Incluso en esta corriente se critica el asimilar o traducir el "buen vivir" - señalado en la Constitución- como sumak kawsay -vida plena-, pues dicho buen vivir constitucional se definiría a partir de patrones occidentales y despoja la dimensión espiritual propio de las culturas ancestrales. ${ }^{3}$

El sumak kawsay es una categoría transversal en nuestra Constitución y es el resultado de la lucha de las nacionalidades indígenas. Principalmente, obedece a un nuevo paradigma apartado de visiones occidentales que, si bien da cuenta de una extrema complejidad, no resulta de imposible realización. Por tal motivo, si nos tomamos en serio la propuesta posdesarrollista -o como alternativa al desarrollo- y biocéntrica plasmada por el constituyente, su construcción resulta indispensable en el marco de nuestro diseño constitucional.

El sumak kawsay responde a la cosmovisión indígena, y esta es su fuente principal para dotarlo de contenido, lo que no implica prescindir de otros conocimientos propios de la filosofía occidental. Todo ejercicio de construcción del sumak kawsay

3. Antonio Luis Hidalgo-Capitán y Ana Patricia Cubillo-Guevara, "Seis debates abiertos sobre el sumak kawsay", Íconos, Revista de Ciencias Sociales, Dossier 18, n. ${ }^{\circ} 48$ (2014): 25-40, doi: https://doi.org/10.17141/ iconos.48.2014. 
debe encontrar acuerdos en sus principios fundamentales, uno de ellos, el respeto de la naturaleza como ente vivo e indispensable para la vida. ${ }^{4}$

Para los movimientos indígenas kechwua consiste en: "vivir en armonía con la comunidad, un respetar al vecino y a la naturaleza, es tener conciencia de que todo está vivo y somos parte de ese todo. Es plenitud total, en donde la noción del yo se transforma en nosotros". ${ }^{5}$ Ariruma Kowii, a partir de una reconstrucción de las formas de pensamiento de los quichuas y una arqueología de las palabras, que implica investigar el habla cotidiana, así como los gestos y rituales, señala que el sumak kawsay "es una concepción andina ancestral de la vida que ha permanecido viva en muchas comunidades indígenas hasta nuestros días. Sumak significa lo que es ideal, bello, bueno, realización, y kawsay es vida, con referencia a una vida digna, en armonía y equilibrio con el universo y el ser humano. En resumen, sumak kawsay indica la plenitud de la vida". ${ }^{6}$

Otros teóricos lo definen como "una cosmovisión de armonía de las comunidades humanas con la naturaleza, en la cual el ser humano es parte de una comunidad de personas que, a su vez, es un elemento constituyente de la misma Pachamama, o madre tierra". ${ }^{7}$ Todo ello consolida una propuesta constitucional desde el alma misma de las culturas milenarias, para lo cual es necesario transformar el modelo civilizatorio y epistémico de interpretación. ${ }^{8}$

Acercándonos a visiones más puras, que intentan construir el sumak kawsay desde la experiencia milenaria propia de los pueblos indígenas, encontramos que este se define como un sistema de vida comunitario en armonía con la naturaleza, desde y con la Pachamama. De modo que el sumak kawsay es el estado de plenitud de toda la comunidad vital, no solo de los seres humanos, sino de todos los elementos que integran la madre naturaleza y que permiten la constitución y la continuidad de la vida. El sistema del sumak kawsay tiene un profundo sentido cósmico y se configura a partir de reconocer la identidad e interacción entre ser humano y naturaleza en un

4. Nina Pacari, "Sumak Kawsay para que tengamos vida", en Antología del pensamiento indigenista ecuatoriano sobre Sumak kawsay, ed. Antonio Luis Hidalgo-Capitán, Alejandro Guillén García y Nancy Déleg Guazha (Huelva: CIM/FIUCUHU / Pydlos, 2014), 345.

5. Gina Maldonado, "el sumak kawsay en la cosmovisión Kechwua". Entrevista realizada por Alexander Barahona, 24 de diciembre de 2013.

6. Ariruma Kowii, “Sumak kawsay”, Revista La Macchina Sognate, 2015, http://www.lamacchinasognante. com/il-sumak-kawsay/.

7. Carolina Silva, “¿Qué es el buen vivir en la Constitución?”, en La Constitución del 2008 en el contexto andino, ed. Ramiro Ávila (Quito: Ministerio de Justicia Derechos Humanos y Cultos, 2008), 112.

8. Rafael Quintero, Las innovaciones conceptuales de la Constitución de 2008 y Sumak Kawsay (Quito: Abya-Yala, 2009), 84. 
escenario de igualdad y correspondencia. ${ }^{9}$ Es decir, el sumak kawsay rompe con la teoría antropocéntrica, sustentada en la dominación y jerarquía del ser humano y en su lugar postula como premisa básica una dualidad armónica que considera por igual a los seres vivos.

Por lo expuesto, el sumak kawsay propone una interpretación intercultural de los preceptos constitucionales, para lo cual cabe repensar el constructo filosófico occidental e incorporar elementos de armonía, complementariedad, comunitarismo, correspondencia y relacionalidad de las personas y sociedad en conjunto con la naturaleza. ${ }^{10}$ Es una nueva forma de interpretar los derechos, la cual no excluye la teoría clásica, sino que la complementa frente a la diversidad y necesidad de construir un método inclusivo que materialice una constitución abierta - pluralista- y aclare las tensiones -epistémicas e interpretativas- que de ella subyacen.

Ahora bien, esta tarea nos plantea un problema metodológico complejo, esto es, la inconveniente práctica de tratar de dotar de un nuevo significado a principios y nociones que han sido abordadas exclusivamente desde teorías antropocéntricas. No obstante, es imprescindible realizar un ejercicio metodológico de armonización que amalgame las diversas visiones que confluyen en la Constitución. Este ejercicio, tanto político como jurídico -dependiendo de las competencias en las que se realice-, permitirá la generación de una hermenéutica intercultural.

Los principios fundamentales en los que se debe sustentar esta interpretación son los previamente citados: i) relacionalidad que consiste en que todo está vinculado y conectado a través de una red de nexos y vínculos, como fuerza vital de todo lo que existe, sin que quede nada por fuera de esta condición. Así, el ser humano como tal se halla dentro de la red de múltiples conexiones. De manera que todo elemento tiene vida y cumple su función con el todo. ${ }^{11}$

Respecto a ii) correspondencia, se destaca que los diferentes niveles de vida, a todo nivel y en todas las categorías (en lo cósmico y en lo humano), se interrelacionan en forma armoniosa, interrelación que no es causal o inferencial, sino simbólica, es decir, una presentación sui generis de la realidad.

En relación a iii) complementariedad, se entiende que nada existe por sí solo en forma individual, sino en complemento, de manera que el ser humano no puede ser

9. Luis Macas, "El Sumak kawsay", en Debates sobre cooperación y modelos de desarrollo. Perspectivas desde la sociedad civil en el Ecuador, coord. Gabriela Weber (Quito: Centro de Investigaciones Ciudad y Observatorio de la Cooperación al Desarrollo en el Ecuador, 2011), 47-55.

10. Raúl Llasag Fernández, "El sumak kawsay y sus restricciones constitucionales", FORO: Revista de Derecho (UASB-Ecuador), 2009, 114-5.

11. Ibíd., 114-5. 
concebido como un sujeto autónomo y separado, en tanto está incompleto. Es en la unidad con los otros y la naturaleza en la que se entiende la integralidad de los seres. En la complementariedad, los opuestos (noche-día, cielo-tierra-bien-mal, etc.) no son contraposiciones excluyentes, sino elementos incluyentes dentro de un todo integral. ${ }^{12}$

Finalmente, en cuanto a iv) reciprocidad, esta refleja el respeto y entrega al otro, pues a todo acto le corresponde otro recíproco como contribución complementaria, por tanto, toda acción será compensada por el receptor en la misma magnitud. ${ }^{13}$

El principio de sumak kawsay representa una forma y/o sistema de vida ancestral, derivado de la cosmovisión y filosofía andina que se traduce "en el consenso, el acuerdo, la sinergia, la empatía, el respeto, y lograr recrear un sistema homeostático de convivencia orgánica con todos los elementos de la vida". ${ }^{14}$ Por ello, concluimos que el referido principio es una forma de ser, ver y actuar propia, producto de un acumulado histórico y milenario de los pueblos indígenas, que constituye la esencia de una forma de vida comunitaria, armónica, en equilibrio interno y externo de la vida huma y natural.

En nuestra Constitución, el sumak kawsay es concebido tanto como principio que orienta los derechos como un fin del desarrollo. Para el constituyente, la naturaleza dejó de ser objeto para ser un sujeto autónomo que debe ser interpretado en forma integral con el ser humano. Así, la dinámica social no se aprecia por fuera del todo natural cuya dinámica tienen vida propia y autónoma cumpliendo ciclos de renovación y cuidado biodiverso. De tal razón que el artículo 71 de la Constitución reconoce que "La naturaleza o pachamama, donde se reproduce o realiza la vida, tiene derecho a que se respete integralmente su existencia y mantenimiento y regeneración de sus ciclos vitales, estructura, funciones y procesos evolutivos".

Es en la celebración de la vida y la comprensión de la interacción entre todos los elementos que la hacen posible donde radica el salto declarativo que ha dado el Ecuador respecto a la jerarquía e interdependencia de los derechos estrictamente humanos, recociendo a la Pachamama - madre tierra, en tanto valor constitucionalizado en el preámbulo de la Constitución- como sujeto de derechos, lo que implica que este reconocimiento se fundamenta en los principios de integralidad, indivisibilidad, universalidad e independencia. ${ }^{15}$

12. Ibíd., 116.

13. Ibíd., 116-7.

14. Atawallpa Oviedo, "El postmoderno Buen Vivir y el ancestral Sumakawsay", en Antología del pensamiento indigenista ecuatoriano sobre Sumak kawsay, ed. Antonio Luis Hidalgo-Capitán, Alejandro Guillén García y Nancy Déleg Guazha (Huelva: CIM/FIUCUHU/Pydlos, 2014), 272.

15. Diana Murcia Riaño, La naturaleza con derechos (Quito: Instituto de Estudios Ecologistas del Tercer Mundo, 2011), 17. 
De lo expuesto se concluye que el método de interpretación del artículo 71 no puede ser otro que el que se deriva de un método intercultural (y los elementos expuestos supra), ya que es a partir de ello que se entiende la ontología de la naturaleza como sujeto de derechos. La Corte Constitucional, si bien no ha desarrollado el contenido de este derecho, ha expuesto a manera de obiter dictum:

Esta nueva visión adoptada a partir de la vigencia de la Constitución de 2008, se pone de manifiesto a lo largo del texto constitucional, es así que el preámbulo de la Norma Suprema establece expresamente que el pueblo soberano del Ecuador: "Celebrando a la naturaleza, la Pacha Mama, de la que somos parte y que es vital para nuestra existencia" ha decidido construir una nueva forma de convivencia ciudadana en diversidad y armonía con la naturaleza, para alcanzar el buen vivir o sumak kawsay. De esta manera el sumak kawsay constituye un fin primordial del Estado, donde esta nueva concepción juega un papel trascendental en tanto promueve un desarrollo social y económico en armonía con la naturaleza. Es así como la importancia de la naturaleza dentro de este nuevo modelo de desarrollo se ve plasmada en el artículo 10 de la Constitución de la República que consagra: "Las personas, comunidades, pueblos, nacionalidades y colectivos son titulares y gozarán de los derechos garantizados en la Constitución y en los instrumentos internacionales. La naturaleza será sujeto de aquellos derechos que le reconozca la Constitución". Así, el Ecuador se convierte en el primer país en reconocer y amparar constitucionalmente los derechos de la naturaleza. ${ }^{16}$

Con este énfasis constitucional, se debe entender que la Constitución exige la necesidad de mirar los derechos -y los derechos de la naturaleza, sobre todo- desde una lógica diferente; es decir, desde la lógica que ha orientado el vivir de los pueblos indígenas y afrodescendientes, la misma que considera a la Pachamama como un ser vivo, con inteligencia, sentimientos y espiritualidad y que se expresa en la filosofía del "buen vivir". Esta lógica genera la presencia de un nuevo constitucionalismo interculturalizado cuya interpretación incluya las cosmovisiones plurales en la determinación de los derechos, fundamentalmente los de la naturaleza. ${ }^{17}$

\section{LA NATURALEZA COMO SUJETO DE DERECHOS. UNA MIRADA DESDE LOS PUEBLOS EN AISLAMIENTO VOLUNTARIO}

Hemos dicho que la naturaleza es sujeto de derechos de manera autónoma y no necesariamente por los beneficios que pueden representar a la sociedad. Ahora, en la

16. Ecuador, Corte Constitucional, "Sentencia 166-15-SEP-CC", en Caso n. 0507-12-EP, 20 de mayo de 2015.

17. Catherine Walsh, Interculturalidad, Estado y sociedad (Quito: Abya-Yala, 2009), 169. 
interpretación, para su efectiva materialización, adquieren especial trascendencia los pueblos indígenas -entre estos los pueblos denominados en aislamiento voluntario, libres o no $\operatorname{contactados}^{18}$-, pues su cosmoconciencia abona a la comprensión de la naturaleza con derechos y a la deconstrucción de paradigmas liberales o antropocéntricos que se contraponen al reconocimiento de derechos fundamentales de otros seres que no sean las personas o que terminan por tolerar un reconocimiento menguado y anclado a los beneficios de la humanidad.

Como lo sostienen Vela Almeida y Alfaro Reyes, ${ }^{19}$ en las nacionalidades indígenas se observa la creación de estructuras míticas y cosmología, cuyas conductas y rituales pueden entenderse como principios ecológicos en los que basan sus normas sociales y económicas con el objetivo de conservar un espacio que sostenga recursos naturales y satisfaga necesidades sociales. Esto ocurre en el marco de conservación de un equilibrio ecológico en el que animales y plantas reciben un respeto individual.

Es así que en la Amazonía ecuatoriana perviven los pueblos denominados en contacto inicial (waorani) y en aislamiento voluntario-no contactados (tagaeri, taromenani). Estos pueblos, conforme al artículo 57 de la Constitución, gozan de una protección especial -en clave biológica y cultural- y desde los cuales se puede o se debe construir la interpretación constitucional, sobre todo, cuando se trate de derechos que precisamente encuentran su origen en estos pueblos y no en la modernidad occidental.

Al realizar una aproximación a los pueblos libres, y más allá de las características propias de su coexistencia, se puede advertir la presencia de ciertos elementos que resultan útiles para fundamentar la naturaleza como sujeto de derechos. Así, la identidad de estos pueblos está dada no solo por esta estrategia de aislamiento y autodeterminación como forma de autoprotegerse en términos de existencia física, sino también como una estrategia que resulta necesaria para mantener la selva virgen. Es decir, para estos pueblos es fundamental la preservación de la naturaleza, y no solamente porque de ella obtienen lo necesario para su supervivencia, sino porque mantienen una conexión simbólica, intangible, espiritual, de veneración y respeto que posibilita su existencia física y cultural.

Muchos de los elementos de la naturaleza a los que desde una visión occidental se asocia como simples espacios de aprovisionamiento de recursos, para los pueblos

18. Debemos destacar que a estos pueblos se les ha dado diferentes denominaciones: pueblos libres, no contactados, ocultos, invisibles, en aislamiento voluntario, etc. Nosotros preferimos denominarlos "pueblos libres" como una forma de reivindicar su derecho a vivir conforme a su autodeterminación y sin presiones de las políticas derivadas de la sociedad occidental.

19. Diana Vela Almeida y Eloy Alfaro Reyes, "Componente antropológico", en Derechos de la Naturaleza: fundamento, contenido y exigibilidad jurisdiccional (Quito: Corte Constitucional del Ecuador / CEDEC, 2013), 215. 
ocultos representan escenarios sagrados que gozan de energía y vitalidad y que deben ser protegidos, en la medida en que "todos los seres de la naturaleza están investidos de energía que es el 'samai' y, en consecuencia, son seres que tienen vida: una piedra, un río (agua), la montaña, el sol, las plantas, en fin, todos los seres tienden vida y ellos también disfrutan de una familia, de alegrías y tristezas al igual que el ser humano". ${ }^{20}$

Tal es así que "las secuencias narrativas de los waoranis, en perspectiva histórica como pueblo, son la de un pasado idílico en el que era dueño de vasto territorio donde abundaba todo lo actualmente escaso o perdido: los animales y sus sonidos, los gigantescos árboles, los frutales, las palmeras, los ríos de agua cristalina, el silencio". ${ }^{21}$

Es decir, entre los pueblos ocultos y el cosmos existe una relación de dualidad inescindible en la que los pueblos y la naturaleza son uno mismo. Todo elemento de la naturaleza es una entidad viva y relacionada y por lo tanto susceptible de contar con derechos y de ser protegida, puesto que todo perjuicio al elemento natural, más allá de que la afectación pueda causar a su vez un perjuicio a la humanidad, afecta su propia existencia. La relación de los pueblos ocultos con la selva es tal que se puede sostener, con cierta credibilidad que, en aras de una evolución conjunta, estos pueblos incluso han llegado a modificar ciertas condiciones de algunos de los elementos de la naturaleza con la finalidad de asegurar la conservación de estos.

Los pueblos libres demuestran una conexión fuerte y armoniosa, en sentido espiritual y cósmico, con la naturaleza y sus recursos, cuidándola y apropiándose solo de aquellos elementos que consideran estrictamente necesarios para su supervivencia, convirtiéndose en los primeros guardianes de los recursos naturales, sus ciclos vitales y regenerativos. Tal como lo resume Ramiro Ávila, al aproximarse a la vida de los waoranis, desde sus inicios estos están estrechamente vinculados con la naturaleza ya que, al ser hijos del sol, están conectados con el cosmos y, al ser padres del jaguar, son parte integrante de la naturaleza. ${ }^{22}$ Para ellos, la relación con la naturaleza es íntima e indisoluble, tanto así que tienen un profundo conocimiento, desde la historia y desde el ambiente, de la selva, de las plantas, de sus procesos de conocimiento, y de los animales. ${ }^{23}$

20. Nina Pacari, "Naturaleza y Territorio desde la mirada de los pueblos indígenas", en Derechos de la Naturaleza el futuro es ahora, comp. Alberto Acosta y Esperanza Martínez (Quito: Abya-Yala, 2009), 32-3.

21. Jimmy Herrera, "Proceso de Diálogo en la franja diversidad y vida del cantón Francisco de Orellana", en El Último grito del jaguar, comp. Ivette Vallejo y Ramiro Ávila (Quito: Abya-Yala, 2009), 220.

22. Ramiro Ávila Santamaría, "La utopía del oprimido. Los derechos de la naturaleza y el buen vivir en el pensamiento crítico, el derecho y la literatura" (tesis doctoral, Universidad del País Vasco, 2016), 314.

23. Ramiro Ávila Santamaría, "Los pueblos en aislamiento y nosotros", en El último grito del jaguar, comp. Ivette Vallejo y Ramiro Ávila (Quito: Abya-Yala, 2009), 66. 
En este contexto, si bien la relación dual a la que hemos hecho referencia resulta aplicable respecto a todas las nacionalidades indígenas, la aproximación teórica realizada en este artículo se centra en los pueblos en aislamiento voluntario debido a dos premisas que resultan particularmente relevantes: i) la primera radica en que los pueblos ocultos, a diferencia del resto de nacionalidades, no mantienen relación alguna - $\mathrm{O}$ mantienen una relación esporádica con personas no indígenas-, de ahí que aún no han sido absorbidos - o sometidos a procesos de aculturación- por la lógica occidental, por ende, en sus formas y en sus posibilidades, exigen el respeto hacia la naturaleza; y ii) debido a la configuración geográfica, los pueblos ocultos son los dueños ancestrales de nuestra selva amazónica que constituye una zona megadiversa cuyos elementos son potencialmente afectados como consecuencia de las políticas extractivas de los recursos naturales no renovables.

De ahí que, en la práctica social, se puede observar ante la presencia de actividades extractivas, que quienes reivindican la naturaleza como sujeto de derechos, como forma de precautelar la naturaleza, en sus formas y en sus posibilidades, son los pueblos libres. De manera que, de no ser por la presencia de los pueblos en aislamiento voluntario, no existiría posibilidad de tutelar a la naturaleza -al menos en sus territorioscomo sujeto de derechos; de allí la urgente necesidad de reivindicar a estos pueblos milenarios y su relación con la Pachamama.

En suma, la cosmoconciencia de estos pueblos en aislamiento voluntario contribuye al debate de un método de interpretación constitucional intercultural que reconcilie la sabiduría andina y las prácticas conservacionistas en relación con las prácticas propias de la modernidad y el desarrollo como derrotero estatal, a partir del respeto a la diferencia cultural en un escenario de igualdad. Esto implica acercarnos a una interpretación constitucional que no se construye exclusivamente en función del constitucionalismo hegemónico, sino que necesita nutrirse de otros saberes populares - constitucionalismo popular-. Dicho de otra forma, enraizados en actores distintos a quienes ostentan el poder político o judicial y de otras disciplinas -antropología, sociología, entre otras-que se complementan con el derecho, debido a lo cual se pueda construir un escenario jurídico que considere y respete por igual, sin ninguna clasificación, a todos los seres vivos.

Cabe subrayar que no se trata de idealizar el mundo indígena o de sobreponer la filosofía andina sobre la filosofía occidental, o de volver al pasado y renegar de la modernidad. Se trata de insertar en el debate, el futuro de las sociedades y los seres humanos, a partir de una vida respetuosa y armónica que nace del conocimiento de los 
pueblos indígenas. Se trata de reivindicar la autodeterminación de estos pueblos para profundizar y extender las prácticas del buen vivir hacia la sociedad. ${ }^{24}$

\section{CONCLUSIONES}

A partir del enfoque epistémico y metodológico desarrollado en el presente artículo, respecto a la naturaleza como sujeto de derechos en relación fundamental con los pueblos libres, queda clara la existencia del reconocimiento de la naturaleza como sujeto de derechos fundamentales. Esto ocurre más allá de que a prima facie aparezca como novedoso, pionero y progresista, pues plantea en términos jurídicos y de interpretación constitucional un problema estructural y argumentativo complejo. Las visiones tradicionales del derecho nos resultan insuficientes o poco idóneas al abordar el debate jurídico respecto al desarrollo y aplicación de dicho reconocimiento. Por tal motivo, las autoridades judiciales enfrentan el reto de tomarse en serio los postulados constitucionales y materializar en la práctica jurídica, a través de sus decisiones, la posibilidad de que un ser vivo no humano cuente con la titularidad de derechos constitucionales de manera autónoma.

Este desafío constitucional exige, al menos en la perspectiva de este estudio, alejarnos de prácticas o paradigmas clásicos de la dogmática jurídica y acercarnos a la construcción de nuevas formas de ver y entender el derecho, a partir de un enfoque que se funde en una distinta matriz epistemológica -intercultural e interdisciplinaria-. El ejercicio hermenéutico resulta el método más plausible al momento de dotar de contenido o desarrollar aquellas categorías jurídicas constitucionales propias o más próximas a la filosofía andina y cuya aplicación material en la realidad jurídica, pese a su reconocimiento constitucional, aparece como muy lejana en momentos actuales.

La Constitución ecuatoriana incorporó un nuevo paradigma de derechos e interpretación, el cual nace desde los pueblos y naturaleza (en relación imbricada), que se sustenta en una epistemología intercultural. Bajo este enfoque, todos los saberes adquieren relevancia en la construcción del modelo de hermenéutica de derechos, pues responde a la diversidad de visiones, tanto en el goce de derechos humanos y de la naturaleza, como en la forma de concebir el desarrollo, conjugando en ambos casos alternativas al modelo hegemónico, sin que ello implique su desplazamiento.

24. Mónica Chuji Gualinga, "Modernidad, desarrollo, interculturalidad y Sumak Kawsay o Buen Vivir", en Antología del Pensamiento indigenista ecuatoriano sobre Sumak Kawsay, ed. Antonio Luis Hidalgo-Capitán, Alejandro Guillén García y Nancy Déleg Guazha (Huelva: CIM/FIUCUHU / Pydlos, 2014), $157-8$. 
Tal como lo sostiene Julio Prieto, el reconocimiento de la naturaleza como sujeto de derechos y su transversalidad en la Constitución implica una nueva lectura de los derechos humanos, con base en una relación complementaria hacia la naturaleza; es decir, leerse de manera complementaria pero autónoma. Esto implica repensar la relación del Estado y sus ciudadanos con los recursos humanos que ya no se sustenta en la titularidad de explotación, sino en reconocer el valor intrínseco de la naturaleza para su mejor protección..$^{25}$

Por lo dicho, el sumak kawsay y la cosmovisión de los pueblos libres nos postulan cinco elementos que contribuyen a la construcción de la epistemología intercultural: i) relacionalidad, ii) complementariedad, iii) correspondencia, iv) reciprocidad, y v) pervivencia, cuyos sentidos y alcances proponen una interrelación con la naturaleza haciendo de ella un sujeto dinámico en interacción permanente con los pueblos. En la medida en que valoremos a la naturaleza y sus ciclos, haciéndonos parte de ellos, entenderemos la importancia de su garantía para nuestra supervivencia como sociedades, así como la importancia de la unidad en la diversidad de visiones en el Estado plurinacional.

Los métodos de interpretación constitucional responden a una lógica antropocéntrica (los más ortodoxos, como el literalista, o los más avanzados, como el teleológico). Urge entonces plantear un método hermenéutico intercultural que involucre las cosmovisiones de los pueblos originarios y mestizos, para dotar de contenido material a los derechos de la naturaleza y así poder armonizar e integrar la Constitución en la jurisprudencia, como en la normativa del ordenamiento. Por tanto, la interpretación intercultural es una apuesta constituyente de retos y desafíos aún por construir.

\section{BIBLIOGRAFÍA}

Ávila, Ramiro. El neoconstitucionalismo andino. Quito: Huaponi, 2016.

- "La utopía del oprimido: los derechos de la naturaleza y el buen vivir en el pensamiento crítico, el derecho y la literatura". Tesis doctoral, Universidad del País Vasco, 2016.

—. "Los pueblos en aislamiento y nosotros". En El último grito del jaguar, compilado por Iván Vallejo y Ramiro Ávila. Quito: Abya-Yala, 2017.

BBC Mundo, "Whanganui, el río en Nueva Zelanda que tiene los mismos derechos que una persona". https://www.bbc.com/mundo/noticias-39291759.

25. Julio Prieto Méndez, Derechos de la Naturaleza. Fundamento, contenido y exigibilidad jurisdiccional (Quito: Corte Constitucional del Ecuador / CEDEC, 2013), 78-9. 
Colombia. Corte Constitucional. "Sentencia T-622/16". En Expediente n. ${ }^{\circ}$ T-5.016.242. 10 de noviembre de 2016.

—. Tribunal Administrativo de Boyacá. "Sentencia". En Juicio de tutela n. 152383333002 20180001601.9 de agosto de 2018.

Confederación de Nacionalidades Indígenas del Ecuador. "Pueblos indígenas en aislamiento voluntario en la Amazonía ecuatoriana". En Pueblos indígenas en aislamiento voluntario y contacto inicial en la Amazonía y el Gran Chaco, editado por Alejandro Parellada. Copenhague: Grupo Internacional de Trabajo sobre Asuntos Indígenas, 2007.

Chuji, Mónica. "Modernidad, desarrollo, interculturalidad y Sumak Kawsay o Buen Vivir". En Antología del pensamiento indigenista ecuatoriano sobre Sumak Kawsay, editado por Antonio Luis Hidalgo-Capitán, Alejando Guillén García y Nancy Déleg Guazha. Huelva: CIM/FIUCUHU/Pydlos, 2014.

Echeverría, Bolívar. La modernidad de lo barroco. Ciudad de México: Era, 1998.

Ecuador. Constitución de la República del Ecuador. Registro Oficial 449, 20 de octubre de 2008.

-. Corte Constitucional. "Sentencia 166-15-SEP-CC". En Caso n. ${ }^{\circ}$ 0507-12-EP. 20 de mayo de 2015.

—. "Sentencia 218-15-SEP-CC". En Caso n. 1281-12-EP. 9 de julio de 2015.

Herrera, Jimmy. "Proceso de Diálogo en la franja diversidad y vida del cantón Francisco de Orellana”. En El Último grito del jaguar, compilado por Ivette Vallejo y Ramiro Ávila. Quito: Abya-Yala, 2009.

Hidalgo-Capitán, Luis, y Ana Cubillo-Guevara. "Seis debates abiertos sobre el sumak kawsay". Íconos, Revista de Ciencias Sociales. Dossier 18, n. ${ }^{\circ} 48$ (2014). Doi: https://doi. org/10.17141/iconos.48.2014.

Kowii, Ariruma. “Sumak Kawsay”. Revista La Macchina Sognate, 2015.

Llasag, Raúl. "El sumak kawsay y sus restricciones constitucionales”. FORO. Revista de Derecho (UASB-Ecuador), 2009.

Macas, Luis. “El Sumak kawsay”. En Debates sobre cooperación y modelos de desarrollo. Perspectivas desde la sociedad civil en el Ecuador, coordinado por Gabriela Weber. Quito: Centro de Investigaciones Ciudad y Observatorio de la Cooperación al Desarrollo en el Ecuador, 2011.

Murcia, Diana. La naturaleza con derechos. Quito: Instituto de Estudios Ecologistas del Tercer Mundo, 2011.

Narváez, Iván. Petróleo y poder: el colapso de un lugar singular Yasuní. Quito: FLACSO, 2009.

Oviedo, Atawallpa. "El postmoderno Buen Vivir y el ancestral Sumakawsay". En Antología del pensamiento indigenista ecuatoriano sobre Sumak Kawsay, editado por Antonio Luis Hidalgo-Capitán, Alejando Guillén García y Nancy Déleg Guazha. Huelva: CIM/FIUCUHU / Pydlos, 2014. 
Pacari, Nina. "Naturaleza y territorio desde la mirada de los pueblos indígenas". En Derechos de la naturaleza: el futuro es ahora, compilado por Alberto Acosta y Esperanza Martínez. Quito: Abya-Yala, 2009.

—. "Sumak Kawsay para que tengamos vida". En Antología del pensamiento indigenista ecuatoriano sobre Sumak kawsay, editado por Antonio Luis Hidalgo-Capitán, Alejandro Guillén García y Nancy Déleg Guazha. Huelva: CIM/FIUCUHU / Pydlos, 2014.

Prieto, Julio. Derechos de la naturaleza: fundamento, contenido y exigibilidad jurisdiccional. Quito: Corte Constitucional del Ecuador / CEDEC, 2013.

Quintero, Rafael. "Las innovaciones conceptuales de la Constitución de 2008 y el Sumak Kawsay". En El Buen Vivir: Una vía para el desarrollo, compilado por Alberto Acosta y Esperanza Martínez. Quito: Abya-Yala, 2009.

Silva, Carolina. “¿Qué es el buen vivir en la Constitución?”. En La Constitución del 2008 en el contexto andino, editado por Ramiro Ávila. Quito: Ministerio de Justicia Derechos Humanos y Cultos, 2008.

Vela, Diana, y Eloy Alfaro. “Componente antropológico”. En Derechos de la naturaleza: fundamento, contenido y exigibilidad jurisdiccional. Quito: Corte Constitucional del Ecuador / CEDEC, 2013.

Walsh, Catherine. Interculturalidad, Estado y sociedad. Quito: Abya-Yala, 2009. 